\title{
LAS DISPUTACIONES METAFÍSICAS DE FRANCISCO SUÁREZ S.J., SU INSPIRACIÓN Y ALGUNAS DE SUS LÍNEAS MAESTRAS. En el IV centenario de la primera edición (1597-1997)
}

\author{
Santiago Fernández Burillo \\ Catedrático de Bachillerato
}

\section{RESUMEN}

Cuatro siglos después de la primera edición de las Disputationes Metaphysicae (1597), esa voluminosa obra sigue siendo la mayor aportación de la filosofía española. Francisco Suárez (1548-1617) es el autor de una de las grandes síntesis del pensamiento escolástico. La clave de su pensamiento y de las «Disputationes» se encuentra en la idea de causalidad o acción libre. Desde este clave se formulan brevemente algunos tópicos: acto y potencia, causalidad, creación. El autor muestra la Metafísica de Suárez desde una óptica existencial y rechaza las acusaciones de abstractismo.

\section{ABSTRACT}

Four centuries after the first edition of Disputationes Metaphysicae (1597), that vast work is still the greatest issue from the Spanish Philosophy. F. Suárez is the author of one of the most important synthesis of the Scholar Philosophy. The key of everything he means, and also of «Disputationes», can be found in the idea of freedom in causality and action. From this concept, some topics are shown: act and potentiality, cause, creation, etc. We explain Suarez's Metaphysics from an existential point of view and refuse the accusation of abstractism.

\section{ELAUTOR Y SU OBRA}

Francisco Suárez, de la Compañía de Jesús, vivió 69 años en tiempos de la Reforma de Trento. Nació en Granda en 1548, nieto de reconquistadores, y, cuando moría en Lisboa, el 25 de septiembre de 1617, jubilado de su cátedra de Teología en Coimbra, nos dejaba una vida de polémicas teológicas y filosóficas y una extensísima obra escrita. Allá en la encrucijada del medievo con la modernidad, Suárez había sido la figura más original de la tradición patrística y escolástica. En esa época la tradición del realismo clásico y medieval se vio puesta a prueba por el luteranismo y el calvinismo, el cisma de Inglaterra, la necesidad de defender la existencia de la libertad y los límites de la autoridad política. Era ésta la misma tradición que renovaba el derecho en sus funda- 
mentos, a raíz del asunto de Indias y las empresas de ultramar. A ninguna de esas realidades tremendas volvió la espalda F. Suárez: nunca fue un erudito metido en su cátedra y sus libros como molusco en la concha.

La docencia fue su vida. Comenzó a enseñar a la edad de 22 años en el Colegio de los Jesuitas de Salamanca, siguió en los de Segovia (1571-74), Ávila y Valladolid (1575-1580) y a la edad de 32 años fue llamado a enseñar Teología en el Colegio Romano. Regresó a la Península en 1585, enseñó en Alcalá hasta 1593 y en Salamanca de 1593 a 1597. Este último año se doctoró en la Universidad de Évora y, por disposición del rey Felipe III, se hizo cargo de la cátedra de Prima en Coimbra, hasta 1615.

De Granada a Lisboa, el itinerario vital de Suárez pasa por diferentes ciudades, colegios y universidades; pero, si un lugar simboliza su vida, es Salamanca. En la Universidad de Salamanca se matriculó en 1561; allí conoció la Compañía y a la edad de 16 años, en tercero de Derecho Canónico, pidió los hábitos. En Salamanca iniciaría su docencia y allí alcanzó la plena madurez. ¿Se podría decir que Suárez es conimbricense, y no salmanticense? Más justo es reconocer que el suarismo es una de las mayores síntesis escolásticas de todos los tiempos.

\section{LAS DISPUTACIONES METAFÍSICAS, EN SU IV CENTENARIO}

En la vida de F. Suárez el año de 1597 significa plenitud, frutos maduros. Aquel año se doctoró y accedió a la cátedra conimbricense de Prima, descanso y reconocimiento que tenía bien merecidos. Aquel mismo año había dado de mano dos obras escritas: los Opuscula Theologica, en que defendía las tesis del molinismo, ${ }^{1}$ y las Disputationes Metaphysicae, con las que prestaba el máximo apoyo racional y filosófico a la Teología de la gracia inspirada en la obra de Molina.

En 1597 hubo un punto límite de tensión; se llegó hasta el máximo de oposición entre escuelas filosófico-teológicas; y se puso por escrito. Llegaba a su extremo el esfuerzo intelectual de la filosofía escolástica española. Y de una misma ciudad salieron para el mundo - y para siemprela mayor controversia y el libro más influyente de la escolástica española del Barroco.

Lo primero que se debe recalcar acerca de la Metafísica de Suárez es lo obvio: que son unas Quaestiones Disputatae, no un tratado sistemático moderno.

He aquí una de las anécdotas más increíbles de la historia de la filosofía: que siendo evidente, por el título, por la forma y por el contenido que esta obra de Suárez es una colección de Quaestiones Disputatae, se le haya atribuído una intención sistemática, se le haya tomado la palabra al pie de la letra (al menos en esto) y se le haga responsable del primer tratado de Ontología, en una línea pre-racionalista que sólo podía alumbrar a Descartes, Leibniz y Wolff.

1 Aunque editados en Madrid el 1599, habían sido enviados a Roma por barco a finales del verano o principios de otoño del 1597 como documentación a favor de Molina para la fase romana de la controversia De Auxiliis (1597-1607). Uso la edición de Lyon: Doctoris Francisci Suarez Granatensis, e Societate Iesu, in Regia Conimbricensi Accademia olim Primarii Theologiae professoris emeriti, Varia Opuscula Theologica, Lugduni, Sumptibus Iacobi Cardon \& Petri Cavellat, MDCXX; 376 páginas a doble columna, en folio de $36 \times 25 \mathrm{~cm}$ más índices. 
Para conmemorar la primera edición de una obra tan importante, lo primero es que no nos equivoquemos acerca del título e inspiración que la anima. Y, como libros tan voluminosos tienen pocos lectores - y esos pocos suelen ser interesados-, importa esclarecer: dar noticia sencilla y amplia del conjunto de ese monumento. Por eso, aceptando la amable sugerencia de esta revista, me propongo exponer la inspiración de fondo y alguna de las líneas maestras de las Disputaciones metafísicas, para quienes no las han leído y, sobre todo, para quienes toman por datos seguros algunos errores que se vienen repitiendo sin razón. Y el primero es éste de la supuesta intención sistemática del autor y su obra.

Por lo demás, como redacto esta colaboración con cierta urgencia - y una síntesis justa y clara es difícil-, pido permiso para moverme en el plano de los resultados. Los argumentos quedarán sólo señalados; ninguno va a ser agotado, y muchos ni siquiera planteados aquí.

\section{TEÓLOGO DE LA GRACIA Y METAFÍSICO DE LA TEOLOGÍA MOLINISTA}

Entre 1593 y 1597 F. Suárez enseñaba y escribía en Salamanca, mientras un debate crispaba los ánimos de sabios y gente llana. La vieja ciudad universitaria era el epicentro de un terremoto espiritual que afectó a toda España: la primera etapa de la polémica De Auxiliis, ${ }^{2}$ en torno a la manera en que Dios concurre con los actos libres humanos, ya sea en el orden natural, ya en el sobrenatural. Las dos tesis encontradas han recibido el nombre de sus autores principales: Luis de Molina, S.J. (1536-1600) y Domingo Báñez, O.P. (1528-1604). Molinismo y bañesianismo son dos soluciones teológicas para el problema de la gracia eficaz, que inclina al hombre a obrar, sin destruir su libre albedrío; ahora, esta Teología de la gracia suponía una pregunta: ¿cómo puede la Libertad divina hacer que el hombre quiera libremente? De modo que la Teología obligaba a repensar el asunto filosófico por excelencia: la conexión entre ser y obrar finito y el Ser y obrar del Infinito.

Molinismo y bañesianismo han quedado para siempre como dos tesis antagónicas en Filosofía más que en Teología. Según Molina, ${ }^{3}$ Dios concurre con nuestro acto libre sin mover eficientemente nuestra voluntad, se trata de un concurso «simultáneo», que se corresponde con la Ciencia Media divina de los futuros contingentes. Por el contrario, según Báñez, ${ }^{4}$ debemos atenernos a principios seguros: primero, que el Autor del ser lo es también del obrar; segundo, que salvo

2 Entre 1588 y 1597 alcanzó tal crudeza en la Península que, denunciado el asunto a la Inquisición, la corona y la nunciatura, el problema fue avocado a Roma por Clemente VIII. La segunda fase tuvo lugar de 1597 a 1607, en Roma. La finalizó el papa Paulo V decretando el carácter meramente filosófico de las divergencias y la igual pertenencia al depósito de la fe de ambas explicaciones de la gracia eficaz.

3 Concordia liberi arbitrii cum gratiae donis, divina praescientia, providentia, praedestinatione et reprobatione, ad nonnullos primae partis $D$. Thomae articulos, Lisboa, 1588 . Se suele citar simplemente como la Concordia y era un tratadito anejo al comentario a la Prima Pars de la Summa Theol. de santo Tomás, que escribió el P. Molina y fue editado en 1592.

4 Tractatus de vera et legitima concordia liberi arbitrii creati cum auxiliis gratiae Dei efficaciter moventis humanam voluntatem, 1599-1600, ed. en Domingo Báñez, O.P., Comentarios inéditos a la Prima Secundae de Santo Tomás, tomo III, «De Gratia Dei» (qq. 109-114), pp. 351-420, Madrid, 1948. 
en Dios todo obrar es la actualización de una potencia; por lo cual, y en tercer lugar, es siempre válido este principio: todo lo que se mueve es movido por otro; por fin, la voluntad humana es movida por Dios como una «moción antecedente», que se corresponde con la Ciencia divina de simple inteligencia, o Presciencia eterna.

Ahora, Domingo Báñez señaló a Suárez como su principal adversario. ${ }^{5}$ Poco más de medio siglo después, el último gran maestro de la escuela tomista, Juan de Santo Tomás, seguía uniendo los nombres de Molina y Suárez. El lector del Cursus Philosophicus Thomisticus ${ }^{6}$ (1663), última gran obra de la escolástica, advierte en seguida que Juan de Santo Tomás considera la obra de Suárez como un clásico.

Pues bien, el juicio de la escuela tomista coetánea acerca de la filosofía de Suárez fue mucho más certero que en nuestro siglo. Los tomistas modernos han considerado a Suárez un filósofo esencialista; en cambio, los de su tiempo, lo vieron como un teólogo que rechaza la teoría aristotélica del acto y la potencia. Para los tomistas del s. XVII, Suárez formula una filosofía que menoscaba la esencia: le hurta realidad «ante rem» y la priva de la condición de coprincipio «in re». Tal como lo ven Báñez y Juan de Sto. Tomás, en Suárez no hay demasiada esencia, sino demasiado poca. ${ }^{7}$ La composición real de esencia y «existencia» que ellos ponen en el ente para explicar toda finitud y causalidad, Suárez la ponía solamente en línea de actualidad; según éste, en el ente finito lo diverso no son esencia y existencia, ${ }^{8}$ sino potencia operativa y acción. ${ }^{9}$ Ahí estaba la verdadera diferencia de pensamiento entre uno y otros. Es cierto que el Dr. Eximio sigue hablando de potencia y acto (véanse las disp. 43, 48 y 49), pero ya no se refiere a la composición entitativa, sino a la

5 «De cuantos adoptan y defienden las opiniones de Molina el principal es Francisco Suárez, quien hasta ha escrito sobre el libre albedrío un tratado en idioma vulgar con intento de defender las doctrinas de la Compañía», D. Bannes, Apologia Fratrum Praedicatorum, etc. Cfr: Scorraille, S.J., El P. Francisco Suárez, de la Compañía de Jesús, según sus cartas, sus demás escritos inéditos y crecido número de documentos nuevos, Barcelona, 1917; vol I, p. 332.

6 Ioannis A S. Thoma, Cursus Philosophicus Thomisticus. Secundum exactam, veram et genuinam Aristotelis et Doctoris Angelici mentem. Nova Editio, Ludovicus Vivès, París, 1883, 3 vols.

7 Juan de Santo Tomás trata la «distinción real» en el vol. II del Cursus, como la tesis más común. Ahora, Suárez no la admite - explica Juan de Santo Tomás-- porque no reconoce realidad a la esencia sin la existencia: «Et haec sententia sumit suum principium ex eo, quod existimat existentiam non distingui a quacunque entitati reali, hoc ipso quod realis est [...] Et hoc ideo, quia remota existentia, omnis realitas removetur, et remanet nihil, et solum in potentia obiectiva, seu in statu possibilitatis, quod est purum nihil sicut res omnes erant antequam producerentur a Deo, et sic solum distinguitur essentia ab existentia, sicut entitas in potentia obiectiva, et in statu possibilitatis a seipsa in statu realitatis extra causas» (o.c., Phil. Nat., I, q. III, a. 2, pp. 49-50).

8 «[... nulla enim essentia potest comparari ad proprium esse ut potentia receptiva, quia oporteret supponi in ratione entitatis actualis, quod involvit repugnantiam. Deinde specialiter in Deo est evidens, quia nulla potentia proprie receptiva potest esse in ipso et maxime potentia ad esse; omnis enim potentia passiva ut sic reducitur in actum ab aliquo agente» (DM, 30, 4, 2).

Suárez siempre refiere esa tesis a Avicena, como extrinsecismo de la existencia, que pasó de Cayetano a los tomistas modernos y a Soto. Cfr. DM, 2, 4, 1 y 2. El realismo exagerado de Avicena, Cayetano y los tomistas no es totalmente distinto del de Duns Escoto, que atribuye a la esencia un «esse diminutum» en la mente divina (Cfr: DM, 31, 2, n. 1); Escoto acepta una cierta realidad de la esencia antes de la creación, como pura posibilidad real (DM, 20, 1, n. 30); y Wicleff afirmó por eso que la creación no es «ex nihilo». A todo ello se opone Suárez.

9 «Denique in omni vera compositione saltem alterum componentium pendet ab alio; quod autem pendet, non potest habere esse a se; prima enim dependentia realis et physica est ab efficienti, sub qua includo finalem, quia est magis metaphorica et quia efficiens propter finem operatur» (DM, 30, 3, 6; cfr: ibídem, 9, n. 40). 
causalidad, esto es, a la gradación de la actualidad eficiente. La potencia pasiva o subjetiva es propia del término de una causalidad imperfecta: transitiva y accidental. Entidad en potencia pasiva sólo es la materia, como receptiva de formas sobrevenidas, sujeto paciente de las acciones transeúntes. Ahora, la distinción entitativa entre agente y paciente es imperfección, y no proviene de la causa eficiente — que, de suyo, no dice imperfección-, sino de la materia. ${ }^{10}$ En la causalidad inmanente, por el contrario, se produce un término en acto (cualidad), pero no en un sujeto material ni externo, sino en el mismo agente. ${ }^{.1} \mathrm{Y}$ en eso se cifra la espiritualidad de las potencias superiores.

En la filosofía de Suárez, la causa transeúnte y la materia se corresponden; a su vez, la eficiencia física es un caso particular de la causalidad. Es causalidad, pero no toda ni la más alta; la causalidad eficiente aristotélica no es la causalidad trascendental. Ahora bien, tal como lo ven Suárez y Báñez, todo lo que deba pensarse de las estructuras metafísicas, sobre todo de potencia y acto, depende de la manera como se entienda la causalidad trascendental. Para Suárez, ser en acto o existencia es lo mismo que ser el término de una acción; a su vez, la acción es la causalidad en acto. Y, a su vez, de nuevo, el ser como tal sólo se entiende a la luz de esa causalidad en acto, porque todo ente es una causa causada o el Origen Incausado, y de esta distinción depende la analogía del ente. En suma, de la causalidad y de la acción, depende por completo toda la teoría sobre el ser.

Insistiré en esto: Suárez — como los tomistas y escotistas— pensó siempre el ser en acto como sinónimo de potestad activa, acción y término de la acción; ya que «el ser es por causa del operar - dice-, por lo cual es proporcionado a la operación y la operación al mismo ser». ${ }^{12}$ Ahora, ¿es erróneo mirar el ser como poder activo y equiparar grados de entidad a grados de potestad eficaz?

Por eso, son ignorancia del asunto las acusaciones de esencialismo, que descalificarían por igual a todas las escuelas de la época. Lo que prueba demasiado, seguramente no prueba nada. Además, bloquean el acceso a la comprensión. No sugiero una visión historicista de la filosofía, solamente mantengo que no se puede valorar lo que se desconoce, o no se comprende; y las valoraciones de ese tipo tienen un doble inconveniente: primero, son injustas y, por tanto, nutren polémicas interminables; $y$, segundo, son ciegas, no ven ni dejan ver, es decir, nos privan de nuestros clásicos y nos empobrecen.

Pero los clásicos están a salvo del tránsito de modas, corrientes y tendencias; más aún, están a salvo de las épocas, no necesitan ser modernos para ser actuales.

10 «n universum in omni agente materiali distinguentur essentialia principia agendi et patiendi, quod non provenit ex praecisa ratione efficientis causae particularis ut sic, sed ex particulari imperfectione substantiae materialis, quae non est activa secundum se totam, sed tantum ratione formae» (DM, 18, 7, n. 53). «Omnis ergo actio transiens, si proprie et in ratione actionis transiens sit, ideo talis dicitur quia est formaliter transiens, id est, ab agente exiens et in passum recepta. Quae rursus dividi potest in plures species et modos actionum transeuntium, quarum tractatio et speculatio propria est physicorum; nam huiusmodi actio maxime concernit materiam sensibilem, ac proinde eadem fere ratio est de actione et de motu quoad has species» (DM, 48, 6, n. 11).

11 «Quia nulla est ratio cur actio immanens ut sic illam distinctionem postulet, immo quodammodo magis erit immanens, si in eodem omnino principio maneat a quo proxime elicitur» (DM, 18, 7, n. 54).

«Hic ergo per actionem immanentem intelligimus veram ac propriam efficientiam quorundam actuum qui manent in ipsis potentiis a quibus fiunt easque informant» (DM, 48, 2, n. 8).

12 DM, 13,14, n. 12. 
La razón para conmemorar el IV centenario de la primera edición de las Disputaciones metafisicas de Suárez sólo puede ser esta: que se trata de un clásico, en el mejor sentido de la palabra. Luego tiene tanto sentido hoy como hace cuatro siglos ir a buscar en su obra asuntos y tematizaciones que ayudarán a pensar más y mejor.

Ahora, para acceder a Suárez, lo primero es evitar la extraña idea de un metafísico puro; no se puede ir a buscar en las Disputaciones de uno de los mayores doctores escolásticos una filosofía «pura». Suárez era un teólogo que, por eso, hizo Filosofía. Y ésta estaba al servicio de la Teología y, en gran medida, pensada en congruencia con ella.

Esta sola observación relativiza, casi hasta marginar al ámbito de las curiosidades y rarezas, la mayoría de las obras recientes sobre la obra del Dr. Eximio.

El teólogo Francisco Suárez es una figura capital de la etapa postridentina. Su aportación está, sobre todo, en el campo de la teología de la gracia. Por ello, quien lea el primero de sus Opúsculos teológicos, titulado «Sobre el concurso, la moción y el auxilio de Dios», verá que contiene la filosofía de la teología molinista que exponen las restantes partes de esa obra. A su vez, ese opúsculo «Sobre el concurso» remite a las Disputaciones metafísicas (lo que autoriza a pensar en una redacción casi simultánea), y concretamente a la disp. 19 sobre la causalidad libre. ${ }^{13}$ Es innecesario acudir a otros motivos para decidir cuál es la inspiración fundamental o la clave de la síntesis suarista: se trata de la causalidad, y de la causalidad libre. Ése es el núcleo «central» de las 54 disputaciones metafísicas. Todas ellas - distribuidas en dos partes-, están pensadas en atención a aquella teoría del ser, de la causalidad y de la acción que concuerda con la definición molinista del libre albedrío. Luego estamos en presencia de una Metafísica que toma como punto de referencia, y como evidencia primera, al ser espiritual y sus operaciones.

El lugar que corresponde a la Metafísica suarista en la historia de la filosofía se comprende mejor cuando se lo pone en contraste con el tomismo y el escotismo, que eran de hecho las referencias que él tomó para tematizar la acción libre, la causalidad y la prioridad del acto.

Para Suárez, el tomismo es deficiente para tratar la causalidad porque la piensa de manera física; por ello da argumentos al determinismo y además deja escapar la trascendentalidad de la acción, que es el acto en su acepción principal. Y el escotismo, según Suárez, si es cierto que evita el fisicismo de la acción, la volatiliza en mera relación inteligible, y, lo que es peor, acentúa el realismo exagerado de lo universal (que ya se da en el tomismo) porque pone la realidad de la esencia como primer término de la operación inmanente divina, previa a la acción «ad extra»: casi hace radicar la creación en una originación en el interior de la Mente divina.

\section{LOS GRANDES TEMAS DE LAS DISPUTACIONES METAFÍSICAS}

Hemos mostrado hasta aquí: a) que el suarismo es una síntesis de filosofía escolástica original; b) que Suárez es el metafísico de la Teología molinista de la gracia; y c) que la clave de su

13 Una lectura de este opúsculo, comparada con la disputación 22, convence del origen molinista de toda la metafísica del Dr. Eximio. 
síntesis es la noción de causa libre; de ella depende toda la teoría de la causalidad, y de ésta la del ser, repartido en ente causado o creatura y Ser Incausado o Creador. Ésta es la inspiración de fondo que anima las Disputaciones metafísicas. Vamos a describir ahora cómo trata Suárez cuatro grandes temas:

1. Causa libre y causalidad inmanente.

2. Potencia y acto.

3. Acción y creaturidad.

4. Duración: Existencia como incontradicción y causa.

\subsection{Causa libre y causalidad inmanente}

Veamos, en primer lugar, cómo la definición de Molina de causa libre comporta una nueva filosofía de la causalidad, y la prioridad del ser como potestad activa.

Los precedentes inmediatos de Molina y Suárez eran: Trento, el calvinismo y el luteranismo.

Formado en el nominalismo agustinista, M. Lutero había planteado la libertad humana en términos de antinomia con la divina: si el hombre fuera libre, Dios no conocería ni causaría los actos humanos; luego afirmar la Libertad omnipotente en el Creador comporta negarla en el hombre. Ante la moción de la gracia divina, el albedrío humano no puede cooperar consintiendo ni obstar resistiendo. La gracia era eficaz por sí sola, y la voluntad humana no recibía de ella un auxilio, sino que era arrebatada. Esa doctrina fue condenada en Trento. La fe católica dice que el hombre merece cooperando con la gracia, porque también puede resistìr y oponerse a ella. La teología moral trata así de la apasionante historia de la salvación personal; nuestra naturaleza caída, con ayuda de la gracia, puede merecer vivir la misma vida divina. Eso dicen las promesas, que fundan la fe teologal y una esperanza razonable en el Dios que salva. A F. Suárez le agradaba citar, en este contexto, una frase muy elocuente de san Bernardo: «Sin libre albedrío, no habría nada que salvar; sin la gracia, nada habría que lo salvara» («Tolle liberum arbitrium, non erit quod salvetur; tolle gratiam, non erit unde salvetur»). Es la libertad, la naturaleza personal y libre, no una physis anónima, lo que importa al teólogo.

Por encima de tópicos, la imagen cristiana del hombre está hecha de afirmaciones y no de negaciones, de equilibrio y no de angustia. Teocentrismo y antropocentrismo no se separan: en virtud de la creación, b heteronomía ontológica, el ser humano posee el ser libre a imagen de Dios, la autonomía práctica. Entre el s. XVI y el XVII, Suárez centró sus enseñanzas en esta tesis positiva: el hombre es el señor de las estrellas. Así se había enseñado en las escuelas desde la era patrística. ¿Influye el cosmos en nuestra alma, nos mueven los astros? Seguramente, pero mediante los estados de ánimo y las emociones; ahora bien, los hombres somos capaces de gobernar nuestros sentimientos, luego los astros. ${ }^{14}$ Esta «fe en el hombre» no es el resultado de una revolución contra la soberanía de Dios, sino todo lo contrario: sólo a condición de creerlo imagen de Dios se puede

14 Santo Tomás de Aquino refería ese argumento a Aristóteles y Ptolomeo. Afirmaron claramente la libertad humana frente a la astrología: Boecio, S. Juan Damasceno y San Agustín. Cfi: Sum. Theol., I-II, q. 9, a. 5, ad 3; De Ver., q. 5, a. 10, c; III Cont. Gent., cap. 84-85. 
depositar razonablemente tanta fe en el hombre. Como Francisco de Vitoria, Tomás Moro, G. Pico della Mirandola, Erasmo y J. Luis Vives, el autor de las Disputaciones metafísicas piensa en los términos de un humanismo creacionista, católico, que no necesita negar nada de Dios para afirmar más en el hombre que cualquier otra teoría.

Trento había reafirmado, en el horizonte de la teología de la creación, la existencia del libre albedrío humano y su capacidad natural (no perdida con el pecado original) para cooperar con la gracia de Dios que restaura y eleva. El auxilio sobrenatural presupone la existencia de la naturaleza libre, dependiente en el ser como creatura y capaz de autodeterminar sus acciones concretas en orden al fin de la vida. Pero hay dos teologías de la gracia, si caben dos maneras de explicar la libertad creada. Suárez pensó que la tomista estaba demasiado ligada a una imagen del mundo físico y que, a pesar de sus intenciones, no superaba el determinismo. La polémica sobre la libertad, entre pensadores católicos fue encendida, apasionada, desmesurada: se cruzaron las acusaciones más duras y las denuncias más graves. Todo comenzó con el libro de Luis de Molina sobre la concordia entre la libertad humana y la acción divina que crea, conserva y coopera. Aquel esfuerzo para interpretar a sto. Tomás iba a desgajar el suarismo del tomismo.

El tomismo era la síntesis de la doctrina aristotélica del acto y la platónica de la participación. De ahí que los principios de su Física parecieran los mismos en Metafísica, salvada la analogía o proporción. Y así, en base al principio aristotélico «todo lo que se mueve es movido por otro», y a la metafísica neoplatónica del Liber De Causis, Tomás de Aquino interpretaba la doctrina patrística de la Presencia de Dios en las cosas en términos de moción. Toda obra de la creatura, como su entidad, es participación del Ser por esencia; luego todo acto humano es movido por Dios, que da la facultad, la conserva y la aplica a la operación.

Para Suárez, esa doctrina solo se salvaría si se prescindiera de la última afirmación («la aplica»), la cual, según él, el propio Tomás de Aquino retractó implícitamente, puesto que habiéndola escrito en De Potentia, no la repetía en las dos Sumas. Pero la exégesis era forzada; estaba en el clima de la polémica. Lo que Suárez rechazaba del tomismo no era sólo la interpretación de los tomistas de su tiempo, como él protestaba, sino también las tesis específicas de Tomás de Aquino; de este modo, estaba erigiendo su propia síntesis.

Para el tomismo, la voluntad humana no puede pasar por sí sola de la potencia de obrar al acto, justamente porque es una potencia. Todavía más, si toda potencia agente debe recibir la actualidad, antes de ejercerla o comunicarla, en el caso de las potencias espirituales - quien argumenta ahora es Báñez- es más necesario todavía, puesto que no están determinadas «ad unum», sino que son indeterminadas, aptas para todo, o capaces de todo, luego más que los brutos, las plantas o los minerales, la voluntad y la razón necesitan ser movidas a obrar, con una moción especial. Esta moción no destruye la libertad, la funda; actúa fuerte y suavemente, de modo que es tan infalible como respetuosa. Si se dice que, puesta la moción divina (un acto de saber y querer eterno), la acción humana no puede ya ser de otro modo, los tomistas, con palabras de santo Tomás, insisten en que lo único necesario ahí es la consecuencia lógica, pero no el consecuente.

Ya el nominalismo y Lutero se habían burlado de esa distinción. Molina y Suárez tampoco la admiten. Si la acción divina se aplica sobre la voluntad humana, la arrebata y no queda libertad para querer de otro modo, ni para dejar de querer; en suma, si es movida pasivamente, no quiere por sí 
misma. «No hay libertad en la potencia pasiva», ${ }^{15}$ repite en uno y otro lugar Suárez; la libertad es indiferencia activa, potestad y dominio de la acción: ${ }^{16}$ dominio activo del propio acto. La misma cosa es voluntad, libertad y causa libre: somos libres también cuando no actuamos. ${ }^{17} \mathrm{Y}$ ello obliga a revisar toda la teoría de la causalidad, empezando por la eficiente. La creatura, como tal, es causa segunda, instrumental y subordinada; pero, como causa, es primera y principal en su orden. ${ }^{18} \mathrm{Y}$ Suárez erige, en base a esto, un principio de alcance trascendental: no se da acción para la acción; ${ }^{19}$ luego el concurso divino es simultáneo.

Ahora, en una teoría del ser totalmente dependiente de la causalidad en acto, de la acción, ese principio aglutina una síntesis de Metafísica nueva, significa una ruptura con el aristotelismo y el tomismo muy importante, aunque no sea total.

Desde este punto de vista, la concordia de Molina tiene su centro en la definición de la libertad; todo depende de esto: que la causa libre es aquella que, una vez puestos todos los requisitos previos a la acción, todavía retiene en sí potestad de obrar o no obrar, o bien de obrar de una manera de modo que también puede obrar lo contrario. ${ }^{20}$

Lo que Suárez afirma, pues, en el punto cardinal de su síntesis de pensamiento es que existe una causa, excelente entre las causas, la voluntad libre, tal que posee dominio de su propio acto, dominio activo, por el cual puede actuar o no actuar, por sí sola. Todavía más, mientras está actuando, la voluntad conserva el dominio de su acto y la potestad sobre él: «voluntas propriissime liber-

15 «Libertas primo et per se cernitur in exercitio actus» (DM, 19, 5, 14). «Potentia passiva ut sic non est libera» (DM. 19, 2, 19). «Dicimus igitur, libertatem arbitrii tolli, si in hac sola indifferentia passiva constituatur» (Opuscula Theol., «De Concursu», cap. 2, n. 2, p. 4). «Primum igitur omnium statuimus, de ratione potentiae formaliter liberae esse, ut quatenus talis est, sit potentia activa» (De Gratia, Prolegomenon I, 2, 1). «Libertas a necessitate non est in patiendo, sed in agendo [...]» (De Gratia, Prolegomenon I, 1, 4).

16 «sse in homine aliquam potentiam activam ex sua vi et intrinseca natura liberam, id est, habentem tale dominium suae actionis ut in eius potestate sit eam exercere aut non exercere, et consequenter una vel aliam seu oppositam actionem elicere» (DM, 19, 2, 18).

«Sit ergo primum huius materiae fundamentum certissimum. Dari in nobis talem libertatem, quae in ipso usu humanorum actuum indifferentiam ad volendum, vel nolendum, habeat, non quod post usum, seu in sensu composito, ut aiunt, stante actuali operatione adhuc maneat indifferentia, sed quod ipse usus sit cum indifferentia, quam retinet potentia etiam in ipso instanti, in quo libere operatur, prout prior natura intelligitur applicata ad operandum cum omnibus requisitis ad agendum, de quo latius Disp. 19. Met. sect. 9» (Op. Theol., loc. cit., n. 6; p. 3).

17 «Liberum arbitrium non in actu vel habitu, sed in potentia aliqua consistere.- Atque hinc quarto concludimus liberum arbitrium creatum directe et formaliter consistere in huiusmodi potentia quae praedictam vim et dominium habet in suum proprium actum. [...] Homo enim liberum arbitrium habet, etiam quando nihil operatur; alias amitteret liberum arbitrium per solam cessationem ab actu, quod absurdum est; non ergo potest liberum arbitrium in actu consistere. Item homo est liberi arbitrii, quia potest operari et non operari, [..]» (DM, 19, 5, 4).

18 «Ut ergo causa sit principalis, non oportet ut sit omnino independens. Et e converso, quod causa sit dependens et indigens auxilio alterius superioris, non satis est ut sit causa instrumentalis» (DM, 17, 2, 15).

19 «Quia ad actionem non est actio, ne in infinitum procedatur, ut Philosophi dicunt: ipsamet igitur actio voluntatis, sicut per se ipsam, et non per aliam actionem manat a voluntate creata, ita et a Deo» (Op. Theol., I, c. 4, 5, p. 11; cfr: $\mathrm{DM}, 22,2,24)$.

20 «Causa libera est, quae, positis omnibus praerequisitis ad agendum, potest agere et non agere, aut ita agere unum ut contrarium etiam agere possit», Molina, Concordia, Ad quaest. 14, a. 13, disp. 3, p. 12, en la ed. de 1588. Francisco Suárez: Cfr: DM, 19, 4, 5; Opuscula Theol., I, c. 3, 2 y 6 pp. 7-8. 
tatem exercet in instanti quo operatur». ${ }^{21}$ Luego por la existencia de la causa libre se demuestra falso el principio «todo lo que se mueve es movido por otro»; no es una verdad universal, luego no es principio. Y la manera como los tomistas entienden la causalidad y la teoría del acto y la potencia, si fuera válida, lo sería solamente en el ámbito físico, lineal. Esa causalidad física, vale para las acciones transitivas, no para las inmanentes. Vale para explicar cómo se propaga un impulso, no para entender cómo se piensa ni cómo se quiere. No queremos porque seamos movidos, insiste Suárez, sino que queremos porque queremos. ${ }^{22} \mathrm{El}$ querer es un acto inmanente; y acción inmanente es aquella cuyo término se recibe en la misma potencia que lo causa.

Lo querido puede ser un objeto externo, pero el término del acto libre de querer es interno, inmanente; ${ }^{23}$ el mismo querer es la acción y el término (es cualidad). Si lo querido es el mismo querer, la libertad está ahí, como hecho evidente: «queremos solamente porque queremos», dice Suárez, y eso lo observa cualquiera en sí mismo. La existencia de la libertad, como la de la causalidad, es algo primero y obvio. ${ }^{24}$

\subsection{Potencia y acto}

El tomismo atribuye valor trascendental a la máxima «todo lo que se mueve, es movido por otro»; porque todo ente finito es compuesto de potencia y acto entitativos; ahora, si el movimiento es la actualización de una potencia, todo ente en potencia que cambia recibe un incremento de actualidad, y no se lo puede dar a sí mismo, ya que es imposible ser en potencia y en acto a la vez y bajo el mismo respecto.

Suárez debía refutar esa máxima si quería demostrar que la premoción física no era una exigencia de la entidad participada; iba a retocar la Física aristotélica y la metafísica tomista, para defender que la voluntad pasa por sí misma al acto, cuando quiere, ya que en eso reside la libertad.

Pero el Dr. Eximio no lo planteó en los términos de una confrontación, sino de hermenéutica: se trata de interpretar correctamente a Aristóteles y a Tomás de Aquino. En particular, se trata de interpretar correctamente este axioma: «Potentia et actus sunt in eodem genere», «el cual es aceptado por muchos como el primer principio en metafísica», dice, debido al testimonio de Aristóteles, del comentador y de santo Tomás. ${ }^{25}$

La interpretación de Suárez pisa sobre las huellas de la de Duns Escoto, pero no es idéntica. Escoto llama «potencia» a la potencia objetiva, esto es, a «una realidad en estado posible antes de

21 «Et in voluntate nihil est actuale in quo primo exerceatur libertas voluntatis nisi actio elicita ab ipsa voluntate; illa ergo est causalitas effectiva talis potentiae» (DM, 18, 10, n. 9). «Dicendum est voluntatis libertatem proprie exerceri in eomet instanti, et circa eundem actum quem praesentem elicit seu exercet» (DM, 19, 9, n.3).

22 «Denique post consultationem mediorum saepe eligimus unum prae alio, SOLUM QUIA VOLUMUS» (DM, 19, $2,15)$.

23 «Nos loqui de libertate creata, quae proxime ac primario exercetur circa actus ipsiusmet facultatis liberae» (DM, 19, 2, n. 21).

24 «Dico ergo primo evidens esse naturali ratione et ipso rerum experimento hominem in multis actibus suis non ferri ex necessitate, sed ex voluntate sua et libertate» (DM, 19, 2, n. 12 y passim).

25 «Eodem principio utitur D. Thomas saepe, signatim I, q. 77, a. 1, ubi inquit: Cum potentia et actus dividant ens et quodlibet genus entis, oportet quod ad idem genus referantur potentia et actus; et ideo si actus non est in genere substantiae, potentia, quae dicitur ad illum actum, non potest esse in genere substantiae»(DM, 14, 2, 3). 
existir en acto» (DM, 14, 2, 13), la cual, como posible, es objeto de la potencia activa. La potencia objetiva y el acto que la realiza están en el mismo género; he aquí la versión escotista. ${ }^{26}$

Era evidente lo común con los tomistas: el trasfondo aviceniano. Pero Escoto había ido por delante en la interpretación de la potencia aristotélica como potencia activa de un sujeto espiritual y libre; y eso es lo que Suárez retendrá de él (cfr. DM, 14, 2, 13). En cambio, Suárez se muestra original al hallar una vía para oponerse al «realismo» aviceniano: la esencia «es» la existencia (disp. 31), y todo ente «es» su unidad, ya sea ésta unidad inteligible o numérica (disp. 4, 5 y 6). No hay universal si no es «post rem», esto es, en la razón y por obra de ella misma, de manera que toda universalidad es, precisivamente considerada, entidad de razón ( $c f r$ : DM, 6, 6, n. 1 y 5-7).

Desde ahora repetirá que esa «potencia objetiva», único sentido en que cabe admitir una potencia trascendental, es puramente lógica y no significa «nada», como no sea la mera no-repugnancia de los términos.

Esta es, pues, la clave para interpretar el principio de toda metafísica aristotélico-tomista: «Se debe, pues, afirmar que aquel axioma se entiende comúnmente de la potencia receptiva o activa» (DM, 14, 2, 14). Desde ahora, «ente en potencia» quiere decir sujeto que recibe una acción, o bien la potencia activa, la facultad capaz de ejercer la acción.

Todo esto conllevaba una reforma de la ontología que remite al tratado De Anima y a la potencia operativa, la acepción clave del término «potencia». Y lo más admirable del caso es que en sus años de docencia en Ávila y Valladolid ya había pensado a fondo su revisión crítica del tomismo y del escotismo; basta con leer lo que el Dr. Eximio dice sobre el término «potencia» en su tratado De Anima ${ }^{27}$ — que significa mera no repugnancia lógica o potestad activa-. Se comprende que en las Disputaciones metafísicas no haya una al principio, para tratar de la división del ente en potencia y acto; no la hay porque esa tesis la repiensa en términos de potencia agente y paciente, esto es, de causalidad.

La distinción entre potencia y acto, si se toma en sentido trascendental, alude al ente posible, esto es, al ente creado. ${ }^{28}$ Ahora bien, en ese sentido ya ha dicho bastante disputando sobre la causa material (disp. 14) y la eficiente (disp. 17, 18 y 19), concluye.

Se ve claro, aquí, cómo es artificioso, forzado, pretender que Suárez haya sustituido la metafísica tomista del acto de ser por una de la esencia posible. Además de la cita anterior, son numerosos los lugares en que repite esta misma idea: «posible», en sentido positivo, significa poder, potestad agente. En sentido negativo, posible es mera no-repugnancia de los términos. Y, en absoluto, nada es posible por esa potencia objetiva, pero sí por la potencia activa (cfr. DM, 20, 1, n. 9-11).

26 Cfr. DM, 14, 2, n. 12-16.

27 De Anima, III, q. 2, n. 4-5.

28 «Priori modo dici solet omne ens dividi per potentiam et actum, vel, ut alii loquuntur, hanc esse unam de proprietatibus disiunctis entis, secundum quam dividitur ens, praesertim creatum, in ens in potentia et in actu, quae divisio explicata a nobis est superius, disp. XXXI, sect. 2 et 3 . Et ibi etiam obiter explicuimus quid sit potentia obiectiva; illa enim, si aliquid est, vel quidquid est, ad hanc potentiam transcendentalem pertinet, de qua etiam potentia potentia obiectiva nonnulla diximus supra, disp. XIV explicando illud axioma: Potentia et actus sunt sub eodem genere. Rursus a potentia transcendenter sumpta denominatur res possibilis, vel potentia logica per non repugnantiam, vel potentia physica per extrinsecam denominationem a potentia agente vel patiente, ut saepe etiam in superioribus tactum est. Denique potentia realis late sumpta, sive activa sive passiva, dicitur de quocumque principio agendi vel patiendi, [...]» (DM, 43, introductio). 
En sentido trascendental, pues, ente en potencia no'es potencia real sino lógica. A su vez, la potencia real es activa o pasiva, según origine o reciba la acción. Luego la potencia real, en la filosofía de Suárez, es siempre de un ente en acto..$^{29} \mathrm{Y}$ el acto real, o se dice en absoluto, y entonces significa la existencia en acto (Dios o creatura) —no la actualización de un sujeto posible — o se dice de forma relativa, esto es, acto de la potencia agente o la paciente, y es la acción (o la pasión), esto es, la causalidad eficiente en acto. ${ }^{30}$

Con esta interpretación del ente en potencia y en acto, ya no repugna que un mismo sujeto, bajo el mismo respecto, esté en potencia para recibir y en acto para producir. Se ha trasladado el tema de potencia y acto a la causalidad; ahora, la pregunta que resta es sólo ésta: ¿es imprescindible que la causa y el efecto sean dos sujetós realmente distintos, esto es, físicamente separados? Es obvio que, si la respuesta fuera afirmativa, sólo habría acciones transitivas; la causalidad eficiente sería sólo cosa de la Física; pero existen operaciones inmanentes, luego, en éstas, la misma facultad está en potencia para recibir y en acto para producir. Otra vez Escoto había desbrozado el camino: nada impide que lo mismo esté en acto virtual o eminente y en potencia formal; y con ello se desmiente el alcance metafísico del axioma «omne quod movetur ab alio movetur». ${ }^{31}$

La causalidad inmanente se pone en primer plano, desde el momento en que demuestra que no es cierto que todo agente deba ser paciente con prioridad, y ser movido para mover. ${ }^{32}$ La distinción entre agente y paciente no es elemento esencial de la causalidad. ${ }^{33}$ Relegada aquella máxima al orden físico, la causalidad debe verse como algo más hondo, incluyendo también la potencia espiritual. Y ahí entra la inmanencia: cuando el paso de potencia a acto no se explica por la pasividad, sino por el poder activo. Una causa es más causa en la medida en que es más poderosa, dotada de mayor potestad o capacidad para obrar por sí misma, y sin necesidad de ser movida.

La tesis molinista conlleva que la voluntad obre sin ser movida, yendo del ser (en acto primero) como potencia, al ser en acto segundo. La operación inmanente es, pues, acto de un acto. Y no se requiere coprincipialidad de potencia pasiva y acto para explicarla, ni que las facultades sean causas recíprocas, según diverso género de causalidad.

29 «Potentia, ut sic, est quidam actus primus, qui dicit habitudinem ad secundum; sed actus secundus proximus et immediatus alicuius potentiae non est nisi aut actio, aut passio; ergo etiam potentia tantum potest esse aut activa aut passiva» (DM, 43, 1, 6).

30 «Actus interdum dicitur absolute, id est, sine respectu ad potentiam agentem vel recipientem, opponiturque potentiae obiectivae excluditque statum existendi tantum in potentia, et sic Deus dicitur actus et intelligentiae et actualis existentiae. De ratione ergo talis actus non est quod sit in subiecto; [...] Alio autem modo sumitur actus relative ad potentiam agentem vel patientem [...]» (DM, 43, 5, 9).

31 Cfr: DM, 18, 7, n. 4.

$32 \ll[\ldots]$ tamen, quod eadem numero facultas simul habeat vim agendi et sit principium recipiendi actionem quam elicit, non potest cum aliqua probabilitate dubitari, supposita VERA DOCTRINA DE ACTIBUS IMMANENTIBUS, qui recipiuntur in eisdem potentiis a quibus eliciuntur, sive ad eam effectionem indigeant aliquo comprincipio, ut specie vel obiecto, aut alio simili, sive non. Nam quidquid in hoc sentiatur, verum nihilominus est EAMDEM FACULTATEM SECUNDUM REM ESSE SIMUL POTENTIAM ACTIVAM ET PASSIVAM RESPECTU EIUSDEM ACTUS et respectu suiipsius, quatenus eundem actum et recipit et elicit» (DM, 43, 2, 14).

33 «Non esse de ratione aut necessitate causae agentis, ut sic, quod distinguatur supposito a patiente» (DM, 18, 7 , n. 52-54). 
La nueva noción de la potencia determinaba un lugar mucho más destacado para la causalidad eficiente, así como la separación drástica de Física y Metafísica. Además, el hylemorfismo suarista ya no es el aristotélico. La distinción real (y la composición real) ya no las concibe Suárez como distinción entre los principios de una cosa, sino como distinción entre cosa y cosa, entidades separables, como son la forma y la materia.

En fin, el horizonte de la Filosofía primera se abre solamente desde la causalidad. Por eso Suárez la incluye en la Prima Pars de las Disputationes Metaphysicae, porque la causalidad está en la entraña de lo que debe entenderse por «trascendental»; en realidad, solo ella es, en lo absoluto, lo trascendental. ${ }^{34}$

La filosofía aristotélica del movimiento es probable para las acciones transeúntes, y falsa para las inmanentes o espirituales. El principio «todo lo que se mueve es movido por otro», al ser falso para la inmanencia, no atañe a la acción como tal, ni al ente trascendental. Era una máxima de observación sensible, una primera experiencia; pero para formular metafísicamente la causalidad se debe atender al hacerse o producirse solamente ("Quidquid fit, ab alio fit; quidquid producitur, ab alio producitur»); sólo esta fórmula es válida (cfr: DM, 29, 1, n. 7, 20-21, 26-27 y 41-42). «Aristóteles no demuestra suficientemente en la Física la existencia de Dios o los atributos propios de Él por solo el movimiento físico - escribe Suárez- [...], sino que allí demuestra con bastante probabilidad la existencia de un primer motor inmóvil. En cambio, en el lib. II de la Metafísica defendió con toda razón y probó la no existencia de un proceso al infinito en las causas eficientes, principio desde el que se llega evidentemente a la conclusión de que es necesario que exista algún ente no producido» (DM, 29, 1, 42).

Si pensamos el ser como una potencia activa, es lógico que la causalidad pase por derecho propio a primer plano: es trascendental como el ser. Y como el ser es análoga. La analogía propiamente dicha - la que media entre el Ser por esencia y los entes creados-es de atribución: fundada en la causalidad. En fin, el primer analogado será lo que sea más ser y más causa, a saber: el Ser incausado. ${ }^{35}$

\subsection{Acción y creaturidad}

Lo más original de Suárez es el hecho de haber tomado la causalidad como principio primero de forma explícita. Ya lo hemos dicho repetidamente: toda su teoría del ente depende de la causalidad; ${ }^{36}$ ente ${ }^{37}$ y causa ${ }^{38}$ son evidencias igualmente inmediatas, es decir, principios. ${ }^{39}$

34 La metafísica suarista es la Filosofía primera porque existen sustancias espirituales y porque las conocemos, lo cual sólo es posible por la inmanencia del entender, que conlleva entender que se entiende y remontarse del intelecto a la Inteligencia increada. En suma, Suárez observa que, sin las inteligencias y Dios, la Filosofía primera debería ser la Física. Cfr: DM, 1, 1, 16 y passim.

35 Cfr: DM, 28, 3, n. 12 y $16-21$.

36 «Quod igitur ad rem spectat, DIVIDITUR HOC LOCO ENS IN DEUM ET CREATURAS» (DM, 28, 1, 3). «Secundo quia ipsa causalitas est veluti proprietas quaedam entis ut sic; nullum est enim ens quod aliquam rationem causae non participet. [...] Nullum autem est ens quod non sit vel effectus vel causa» (DM, 12, provemitum).

37 «Quod ens sit, ita per se notum est, ut nulla declaratione indigeat» (DM, 2, prooemium).

38 «Non inquirimus an causa sit, quia nihil est per se notius» (DM, 12, 1, 1). «Non est autem necessarium quaerere an haec causa sit,... quia nihil est evidentius et notius experientia» (DM, 17, «De causa efficienti in communi», Prooemium).

39 «Principium esse id unde aliquid est, aut fit, aut cognoscitur» (DM, 12, 1, 12). «Haec autem ratio principii cum causalitate coniuncta est respectu creaturarum, et convenit tum Deo, tum etiam creaturis. Et hac ratione potest de Deo et 
Ahora bien, la noción de causa donde se halla plena es en la causa eficiente ${ }^{40}$ las demás causas lo son sólo si se las reduce a ésta, y, por tanto, la acción, antes que accidente predicamental, ocupa lugar y funciones de principio. «Acción» significa, pues, la causalidad o eficiencia en acto ${ }^{41}$ pero la eficiencia - la acción-, no se encuentra sino en el efecto: es la dependencia del efecto respecto de su causa. Suárez entiende dependencia, acción y causa en acto como una misma cosa; así, no cabría decir que la dependencia resulta en el efecto de la acción —o que el efecto depende porque es hecho--, como si la acción fuera primero y la dependencia después; no: la dependencia es la acción. ${ }^{42}$

Pero, si acción es dependencia en el ser, significa por sí misma respectividad, referencia al agente del que dimana; $y$, en fin, como acto último de la potencia, es originación, o vía al efecto. ${ }^{43}$ No hay acción sin término; es esencial a la acción la referencia a un término (DM, 48, 2, 16).

$\mathrm{Si}$ ahora tomamos en cuenta a la vez todos esos aspectos, salta a la vista que en cualquier ente hay una respectividad a la causa que sólo se entiende como dependencia de Dios, o creaturidad. La creaturidad es tan inmediata como la noción de acción o causalidad: «Tengo por verdad —dice Suárezque ninguna acción de Dios en las criaturas es tan evidente como la creación» (DM, 30, 7, 22).

Se dirá que Suárez daba por supuesta la creación. Pero préstese atención a lo que Suárez entiende por acción, y se verá, ante todo que la acción sólo existe o está en el término, no en el agente; ${ }^{44}$ y que la acción significa, a la vez e inseparablemente, vía al término y dependencia del mismo respecto de su causa. La acción es la causalidad eficiente; luego es una noción primera y evidente, por doble título. Y de todas las acciones, la más honda y primera es la creación. Pues bien, en el estudio de la creación, Suárez es muy original; su tratamiento es brillante y, para apreciarlo, se debe saber con qué tesis se contrastaba.

Quien reconozca que todo lo que carece evidentemente de ser absoluto es creado dirá que la creación es una clase de evidencia inmediata. De hecho, en la época de Suárez todos razonaban así.

Los tomistas, supuesta la creaturidad, se aplicaban a deducir de ella la estructura metafísica de los entes. No inferían de la distinción de esencia y existencia la creaturidad, sino al contrario: supuesto que el ente es creado, no hallaban mejor manera de exponer el hecho que la composición de potencia y acto entitativos. Por eso mismo, pensaban la «existentia» como acción que realiza una esencia posible. Ahora, santo Tomás de Aquino enseña que el acto de ser es, de suyo, perfección sin límite; luego ellos enseñan que la acción — la causalidad eficiente en acto—es, de por sí, perfección absoluta. De ahí que, en todo ente creado, la existencia o actualidad de ser deba encontrarse limitada, «coartada» por la capacidad de una potencia subjetiva de ser, la esencia.

creaturis dici secundum analogiam attributionis; verbi gratia, esse principium efficiens analogice dicitur de Deo et creaturis $[\ldots] \gg(\mathrm{DM}, 12,1,15)$.

40 «in omni vera causalitate intercedit aliqua efficiens causa» (DM, 23, 9, 3).

41 «efficientia et actio idem sunt, sicut efficiens et agens» (DM, 18, 11,3). «Causalitatem efficientis causae in nullo posse alio consistere quam in actione» (DM, 18, 10,5). «De actione [...] multa dicta sunt a nobis in superioribus, cum de causa efficiente ageremus. Nam cum actio sit causalitas causae efficientis [...]» (DM, 48, prol., 2).

42 «Dices: dependentia oritur ex actione; ideo enim effectus pendet quia fit; ergo non potest actio esse ipsa dependentia, sed aliquid prius illa. Respondetur negando dependentiam oriri ex actione, sed potius esse ipsamet actionem» (DM, $48,1,16)$.

43 Cfr: DM, 48, 1, n: 17-20.

44 Cfr: DM, 48, 4, n. 11-18. 
Con otras palabras, la manera de entender el ente creado en la escuela tomista del Barroco asumía la evidencia de la causalidad y, además, que esa evidencia era la misma del existir en acto. Ambas cosas, causalidad y ser de existencia, eran virtualmente infinitas, de modo que la explicación de la finitud recaía sobre la esencia.

La lectura actualista de santo Tomás, dio la idea de que la acción (causa eficiente), si fuera acción pura, sería Dios mismo. Se trataba de una constante de escuela: «Así, pues, Cayetano y los que le siguen entienden [...] —reseña Suárez— que la acción expresa una referencia intrínseca a algún sujeto en que inhiere, y que este sujeto tiene que ser el agente mismo. Y si se insta que la acción de Dios no puede estar inherente en Dios, responden que también la acción de Dios está en Dios, pero no por una inherencia propia, sino en virtud de su identidad y simplicidad, porque esa acción no es del género de la acción, ni es un accidente, sino que es la sustancia misma de Dios». ${ }^{45}$

La misma idea se repite en Juan de sto. Tomás: ${ }^{46}$ y Báñez es muy explícito: «la acción, como tal, pensada en sí y no en su término, no dice limitación, sino infinitud y no puede atribuirse más que a Dios, a Quien conviene el obrar sin límite». ${ }^{47}$

La identificación de «actus essendi» como «actio causandi» (permítaseme decirlo así) es característica de la escuela tomista del Renacimiento y el Barroco y no se ha cuestionado hasta el s. XX. Esa confusión explica por qué los tomistas se mostraron condescendientes, o vacilantes, a la hora de formular la distinción real de esencia y existencia: con tal de que no fuera reducida a mera distinción lógica, se contentaban con una distinción «ex natura rei» o modal. Era sintomático. Se entendía entonces — y así lo entiende también Suárez, educado por tomistas— que la distinción «real»es aquella (entre cosa y cosa) cuyo signo es la separabilidad física; y cuando la separación no es posible para nosotros, todavía puede serlo, sin contradicción, para la Omnipotencia divina. De Potentia absoluta Dei, lo que de suyo es una parte incompleta, podría ser aguantado como si fuera un ser completo; se trataría de una intervención divina pero, por ello mismo, posible. Cuando, en fin, ni siquiera De Potentia absoluta cupiera ser aparte, entonces la distinción sería de razón y no real.

Pues bien, las distinciones modales admitidas por los tomistas de entonces eran unas cuantas: subsistencia, existencia y devenir son «modos» de la esencia o naturaleza completa. Y, en suma, si la existencia ya es realmente distinta de la esencia con ser un «modo» suyo ${ }^{48}$, eso significa que la

\section{$45 \mathrm{DM}, 48,4,3$.}

46 «Si autem actus secundus inveniretur purificatus ab imperfectione accidentis, et in linea substantiali, ille esset perfectissimus, et plusquam anima, sicut in Deo, qui est actus purus». Cursus Philosophicus, Pars III, De Anima, q. 1, a. 1, p. 185b; vol. III de la edición Vivès.

47 «At vero de actione, ut significatur per hanc vocem actio, abstrahente ab omni specie et modo actionis; ut per se primo alicui competat, necessum est, quod conveniat Ei secundum se totum: QUONIAM ACTIO, UT SIC, EX EO QUOD NULLAM LIMITATIONEM IMPORTAT, NECESSARIO REDUCENDA EST AD AGENS, CUI PRIMO ET PER SE ET SINE ALIQUA LIMITATIONE CONVENIAT AGERE; et consequenter non ratione alicuius determinatae partis, atque adeo secundum se totum». Domingo Báñez, Scholastica Commentaria In Primam Partem Summae Theologicae S. Thomae Aquinatis, «De Deo Uno», edición facsímil, Valencia, F.E.D.A. 1934, p. 124a.

48 Después de disputar qué clase de distinción «real» media entre esencia y existencia, Báñez se decide por la «real» en sentido fuerte. Es más probable, dice: «Unde sit secunda conclusio. Multo probabilior sententia est et ad rem theologicam magis accomodata, quod esse realiter tanquam res a re distinguitur ab essentia. Haec conclusio videtur esse D. Tho. in locis citatis. Et probatur [...]» (o.c., 147a). La distinción no es apodíctica; no es una evidencia, sino una opinión acorde con la Fe. Se comprende su tolerancia frente a la tesis de la distinción modal; también ésta es «acomodada a los asun- 
esencia puede ser un ente, sostenido por el Poder divino, sin estar actualizada por una existencia; y al contrario, esa misma esencia que ya tiene una realidad en la Mente de Dios, puede tenerla «fuera», si Él le confiere el existir.

Suárez consideró que aquel tomismo - no santo Tomás - atribuía a la esencia demasiada realidad, porque la hacía sujeto de la existencia. Esa clase de entidad en potencia pasiva -replica el Dr. Eximio- es propia de la materia ${ }^{49}$ si no es la potencialidad trascendental, es decir, sólo objetiva o ideal. Y la potencia objetiva, sin la existencia, no es nada.

La creación no se ve, según Suárez, por la infinita perfección de la acción, actualmente limitada por la esencia. Él invierte ese planteamiento: lo evidente es que la acción, como tal, es algo imperfecto.$^{50}$ Por tanto, la acción no se puede ni debe pensar como «perfectio separata» 0 absoluta, ni como agente. Si es la vía al efecto y su dependencia, es obviamente finita, como todos los efectos.

Resumamos. Para los tomistas era evidente que una acción absoluta sería Dios; la acción, de suyo, es lo separado. Y Suárez dice que lo evidente es lo contrario: su limitación. En el caso de cualquier acción, es evidente que es limitada y que se acaba en un término finito; luego que el ente finito es dependiente, en su entidad, es una evidencia igual a la de su existencia.

Ahora, la acción, en la metafísica de Suárez, se divide en inmanente y transitiva, pero no en finita e infinita: sólo hay acciones finitas, porque terminarse en un efecto y depender de otro sólo convienen a la finitud. Por tanto, nada hay - como elemento ni como principio constitutivo- en los entes, que de suyo sea infinito; en el universo de Suárez, los entes creados son sólo finitud. ¿De dónde arranca, entonces, la «reductio in fundamentum»?, ¿de dónde la visión de la creaturidad y el medio para demostrar la existencia de Dios?

Eso equivale a preguntar qué posibilidades tenemos de salir de esta estrechez, razonable y apodícticamente. Deben leerse las disp. 20, 21 y 22, considerándolas como el núcleo temático de la metafísica de Suárez, si es verdad, como hemos repetido, que toda su teoría del ente depende de su teoría de la causalidad o, mejor, que ambas son una misma teoría. Ahora, para una acción, tan constitutiva como su término es la idea de inicio: el término de una acción es un inicio; y tan pronto como es, empieza a depender.

La acción y su término son evidentemente finitos y, en ese sentido, no hay en el ente creado más que limitación. Mas el término de una acción es también novedad, un comienzo. La existencia es novedad, tanto surgiendo como perdurando. Pero un inicio que no se diluye en el transcurrir físico plantea una referencia: remite a su origen. La novedad, en el ser, es dependencia.

Para Suárez, la cuestión se plantea así: la Metafísica ve a Dios antes como Causa que como Primer ente; luego lo primero es el tema de la creación. Y la eficiencia de la Causa primera pone

tos teológicos»: «Nihilominus sit ultima conclusio. Sententia tamen Scoti secundo loco posita, et sententia M. Soto, quae parum differt ab illa, potest probabiliter sustineri [...]. Nos tamen sententiam D. Thomae, ut intelligit Capreolus et Caietan. sequimur» (o.c., 147b).

49 «Nam illud ens quod est pure actuale in existendo, etiam est in se simpliciter purus actus [...], quia ubicumque est aliquod genus passivae potentiae, est etiam aliqua ratio materialis causae; materiali autem causae necessario respondet causa efficiens quae ex illa vel in illam operetur eamque in actum reducat $[\ldots] \gg(D M, 28,1,16)$. 
en los entes una triple dependencia respecto de Él: «Esa dependencia - dice- puede ser o considerarse de tres modos, a saber, en la producción, en la conservación y en la operación»; y continúa así: la dependencia en el hacerse («in fieri»), es la creación, y da el ser como inicio. ${ }^{51}$ Está claro que fieri, llegar a ser, es inicio («cum novitate essendi») (2) $^{5}$ que no se trata de un devenir puro: algo llega a ser. Dure mucho o dure poco, la novedad es el ser. ${ }^{53}$

Es bastante claro que si todo ente es término de una acción, su existir es comienzo. Sólo resta una pregunta: si ese existir o comenzar está en el mismo plano que los cambios físicos o temporales; o, lo que es igual, si puede depender de la materia.

Quienes insisten en presentar la existencia del ente, en la metafísica de Suárez, como mero «non-nihil» y como la ingenua objetivación de una negación absoluta, trasplantada fuera de la intencionalidad de la conciencia por una doble ingenuidad; éstos no han leído a Suárez, sino que usan sus textos y los citan; además, se obstinan en negar la evidencia del ser real como novedad y acaecer. ${ }^{54}$ Pero Suárez no dice eso; dice que ser es inicio, novedad de una acción, y también dice que toda acción es una generación o una creación: ${ }^{.5}$ «tertium non datur!». Ahora la cuestión es, si para empezar a ser basta con la generación de la materia o no. El Dios del paganismo ordenaba el mundo a partir del Caos, que era la materia, no creaba (DM, 20, 1, 23). «Sin embargo, que esto es ajeno a toda razón natural puede probarse primeramente - arguye - por la imperfección de la materia prima; en efecto, siendo ella la ínfima de todas las sustancias, incluso de las corruptibles, resulta increíble que posea esa perfección suma que consiste en tener el ser por sí misma, perfección de la que no son capaces todas las demás especies de realidades generables, ni tampoco sus formas» (DM, 20, 1, 18). Si la materia tuviera el ser por sí misma - continúa - constituiría una sustancia; y esa sustancia sería autosuficiente, necesaria, y no podría dejar de ser. Luego no podría servir para otras generaciones, ya que permanecería siempre la misma en su ser, contra toda evidencia.

51 «Dependentia autem in fieri potissimum in creatione consistit, tum quia haec est propria dependentia entis in quantum ens quam hic inquirimus; tum etiam quia in hac actione consistit primum fieri (ut ita dicam) entium factibilium; et ideo de hac actione dicemus in hac disputatione; nam alii modi quibus prima causa potest res producere, et difficultatem non habent et attingentur satis in disputationibus sequentibus» (DM, 20, prooemium).

52 «Alii distinctione utuntur, dicentes Aristotelem non cognovisse creationem cum novitate essendi, cognovisse autem creationem per modum dimanationis naturalis et eternae a primo ente, et hoc modo posuisse res incorruptibiles manasse a Deo ex aeternitate». Es la tesis del necesitarismo greco-árabe; luego o «novedad» 0 «emanación natural» son cosas contrarias: sólo la «novedad del ser» es la creación.

53 Et hoc modo est verissima propositio, quia per creationem per se primo fit res secundum totam rationem entis, eo quod creatio nullam rationem entis in ea supponat. Nam, iuxta doctrinam Aristotelis, illud dicitur per se primo fieri quod nullo modo supponitur in re quae fit; fieri ergo ens in quantum ens nihil aliud est quam quod ipsamet ratio entis per se primo fiat in tali effectu per talem actionem» (XX, 1, 29).

54 El esfuerzo más inteligente, en ese sentido, sigue siendo el de Angelo Gnemmi, Il fondamento metafisico. Analisi di struttura sulle «Disputationes Metaphysicae» di F. Suárez, Milán, Pubblicazioni dell’Università del S. Cuore, 1969. Le dediqué un amplia reseña-artículo: «Suárez y el Ontologismo», Cuadernos Salmantinos de Filosofia, XX (1993), pp. 213243. Más erudito y documentado, y también más reciente, aunque desorientado en el mismo sentido: Jean-François Courtine, Suarez et le Système de la Métaphysique, París, PUF, 1990.

55 «Illa autem particula ex nihilo, ut distinguat hanc actionem ab aliis, excludit omnem concursum causae materialis et dependentiam rei quae creatur ab aliquo subiecto, ut recte exponit Anselm., in Monolog., c. 8, ita ut idem sit dictum ex nihilo quod ex nullo subiecto; atque ita distinguitur haec actio ab alia quae est per eductionem de potentia subiecti. Hae namque duae actiones adaequate dividunt omnem efficientiam» (DM, 20, 1, 1). 
El ser ¿dice inicio temporal, y solamente temporal (=de la materia), o dice inicio absoluto? Y la respuesta del mismo Dr. Eximio es que el existir sólo es posible por una potencia activa proporcionada; por la materia sólo se explican los cambios, no el ser. La Potencia creadora debe ponerse desde el momento que es evidente que hay entes causados.

Luego ¿puede demostrarse la creación? Sí, responde Suárez, porque «por este mundo visible es posible demostrar que Dios existe, ya que las mismas criaturas claman que tienen otro Autor o Hacedor» (DM, 20, 1, 7). Está claro, pues, que Suárez no separa la demostración de la existencia de Dios de la ostensión de la creaturidad. Y, en efecto, pueden demostrarse ambas cosas: que la creación es «posible» y que existe, luego Dios existe (DM, 20, 1, 8). Ahora bien, ¿cómo se concluye que la creación existe de hecho? Porque sólo es posible por la Potencia divina, no por la potencia pasiva de la materia y menos aún por la objetiva o lógica; ahora bien, existen los efectos, luego tal existir es una novedad de ser que no resulta de la materia ni de la nada.

La Potencia creadora debe admitirse en Dios porque expresa una perfección absoluta. En fin, «a estas razones se añaden otras que de suyo son bastante probables, pues este modo de obrar sin depender de otra causa extrínseca, ya sea eficiente, ya material, está muy de acuerdo con la esencial perfección del primer ente. En primer lugar, porque el modo de obrar es proporcional al modo de ser; pero el modo de ser del primer ente es con toda independencia; luego igualmente su modo propio de obrar será independiente de toda causa, incluso material. [...] En tercer lugar, porque está muy acorde con la razón el que en Dios se dé una potencia de naturaleza superior a la de cualquier otro agente natural o creado; ahora bien, todos los demás agentes necesitan un sujeto para obrar; luego la potencia divina no debe ser tan indigente, sino que, cuanto más perfecta es, tanto más libre ha de encontrarse para obrar, sobre todo porque esa superioridad se da en todos los grados y perfecciones posibles» (DM, 20, 1, 14).

Ahora, al poner toda la acción causal en la existencia dependiente del efecto, Suárez ha «liberado» la causalidad. Es decir, ha resuelto la aporía de la causa, pues la causalidad no es real, a menos que el efecto sea novedad y tenga el ser por la causa. Mas eso no significa que el efecto «salga» de la causa. Si saliera de ella, no sería auténtica novedad, ni recibiría un ser «nuevo». Suárez define la causalidad por la alteridad y novedad del ser del efecto. ${ }^{56} \mathrm{Y}$ de ahí la firme oposición a Escoto, ${ }^{57}$ porque ser producida «ex nihilo» significa que la existencia es novedad, un inicio absoluto (no cronológico).

56 «Causa est principium per se influens esse in aliud» (DM, 12, 2, 4). «Para explicar esto dije que la causa es la que infunde el ser en otro; pues con estas palabras se significa la misma realidad que se supone en el verbo depender; ya que con ella queda significado que para la causalidad es necesario que aquel ser que la causa infunde esencial y primariamente en el efecto, sea causado por la misma causa y, por consiguiente, que sea un ser distinto del propio ser que tiene en sí la causa. Por lo cual, depender en su ser de otro es propiamente esto, a saber: tener un ser distinto de aquél y participado o que de algún modo fluye del ser de aquél» (DM, 12, 2, 7; cfr: ibídem, n. 10).

57 «En cuanto a la última demostración, tomada del hecho de que el ser de la esencia de las cosas se presupone a su creación, quienes estiman que el ser de la esencia es en sí mismo algo eterno, quizá afirmaran que la creación es a partir de la nada de la existencia, mas no de la esencia. Por su parte, Wiclef dijo que la creación no es una producción de la nada absoluta, sino del ser inteligible al ser fuera de Dios [...]. Así mismo Escoto, In II, dist. 1, q. 2, afirma que la creación es una producción de la nada, es decir, no de algo según el ser de la existencia ni según el ser de la esencia, y, sin embargo, no de la nada, es decir, de lo que no es en modo alguno ente, ni absoluta ni relativamente; mas supone que las cosas tienen un ser conocido antes de ser producidas. Pero la verdad es que el ser de la esencia de la criatura, o el ser conocido o inteligible, no es nada real fuera de Dios, según diremos ampliamente después, en la disputación sobre la esencia y la existencia de la criatura» $(\mathrm{XX}, 1,30)$. 
En fin, cuando Suárez niega que la acción perfeccione al agente, quiere decir que el agente obra con espontaneidad, o que no es «movido por otro» para actuar. Y también que la acción pone el efecto y está en él.

Si la acción perfeccionara al agente, el efecto no sería novedad: la causa no sería principio de un ente real, que ha recibido de él el ser. El efecto, tendría que pasar de un agente a otro, como un paquete pasa por las manos de los empleados del servicio de correos: no recibiría de ellos el ser, sólo el cambio de lugar. Si obrar perfeccionara al agente, la causa sería el efecto. No originaría el ser del efecto, solamente le daría curso a lo largo de una cadena de transferencias físicas; ser un efecto sería ir pasando de mano en mano, hasta descansar en uno. Por el contrario, si el efecto recibe el ser de la causa, hace falta que sea novedad y que dependa de aquélla. ${ }^{58}$ Pero una causa que sólo comunica la acción que previamente recibe no suscita novedad ni dependencia esencial.

La acción no es un accidente que inhiere en el agente; luego sólo queda que sea absoluta (tesis tomista) o que sea un modo del término, del efecto mismo.

Por otra parte, a Suárez le parece muy bien que allí donde Tomás de Aquino habla de participación entendamos causalidad; pero no admite lo inverso, pensar la causa y su efecto como partes de un todo (acto de ser, acción pura): eso sería la contracción de una plenitud venida a menos, como algo «ajeno» al agente, y no como el venir a ser del término.

La composición de «este» y «ente», propia del «habens esse», es necesaria si «esse» significa, de suyo, la perfección sin límite y lo absoluto; de ese modo, tener el ser es tener «limitadamente» lo perfectísimo: tener y no tener.

Pero el ser así entendido se asimila a un universal, y la participación trascendental se asimila a la predicamental, y la estructura entitativa a la predicativa: la de sujeto y forma. Ahora, Suárez ha dicho que no admite tal estructura, desde el momento en que afirma que la singularidad pertenece al ente real sin añadido ni determinación extraña al mismo ser. Por lo tanto, lo que es realmente un ente, es «este ente»; sin que ello signifique que es obvia la «limitación» de la perfección infinita 0 absoluta. En suma: Suárez no admite que haya una participación del ser. Para él, lo gradual no es el ser, sino la causalidad, la potencia activa.

Suárez rechazó siempre la universalidad objetiva como universal «in essendo»; y su universalidad «in causando» es potestad: a mayor potestad, mayor universalidad. Pero la causa no precontiene al efecto, eso es absurdo. Y el Creador no precontiene a las creaturas, a modo de posibles ideales, que antecedieran a la existencia, como si esperaran la existencia en la antesala de un contrato laboral. En el universo de Suárez no existe ninguna esencia que esté en el desempleo de la existencia. En Dios y en su Ciencia solamente están como esencias los existentes; lo otro que se le puede atribuir es ente de razón (=nada); y tal atribución es denominación extrínseca, podemos pensar así si queremos, con tal de que no pretendamos estar pensando nada real.

58 «Ultimus autem et proprius sensus est ut illud in quantum specificative tantum sumatur. Et hoc modo est verissima propositio, quia per creationem per se primo fit res secundum totam rationem entis, eo quod creatio nullam rationem entis in ea supponat. Nam, iuxta doctrinam Aristotelis, illud dicitur per se primo fieri quod nullo modo supponitur in re quae fit; fieri ergo ens in quantum ens nihil aliud est quam quod ipsamet ratio entis per se primo fiat in tali effectu per talem actionem» (DM, 20, 1, 29). 


\section{DURACIÓN: LA EXISTENCIA COMO INCONTRADICCIÓN Y CAUSA}

Todos los entes son causas causadas, poderosos para obrar pero radicalmente dependientes en el ser. El verdadero ser en acto es potencia activa; luego los grados del ser son los grados de la causalidad. En el universo de Suárez los grados del ser no son una escala de esencias actualizadas, sino de potencias activas; ${ }^{59}$ lo que diferencia a las piedras de las plantas o de los animales brutos y a éstos de los hombres, los ángeles y, en fin, de Dios, es su respectivo grado de ser, es decir, los diversos niveles de poder activo. El poder de obrar —enseña Suárez- o no es algo distinto del tipo de entidad o, si ponemos una distinción de razón, se debe respetar el paralelismo: grado de ser y de poder activo se conmensuran. ${ }^{60}$ Hay causas finitas, naturales o espirituales y, sobre todas ellas el Poder del Incausado, o Ser «a se». ${ }^{61}$ De modo que el atributo más propio de Dios es Ser Incausado: «esse a se et sine efficientia ab alio» (DM, XXIX, 1, 41), y todos los demás atributos se deducen de éste, dice Suárez.

El constitutivo de la creatura es la dependencia: «Pues, aunque la misma dependencia actual sea algo ex natura rei distinto del mismo ente creado, no obstante, la misma aptitud y necesidad de depender le es intrínseca y esencial; y no parece que pueda concebirse o existir sin el respecto y referencia trascendental a aquel de quien depende, en el cual respecto parece consistir sobre todo la potencialidad e imperfección del ente creado en cuanto tal». ${ }^{62}$

Luego la dependencia que hay en la creatura respecto de Dios no es un accidente, sino algo constitutivo. Se distingue modalmente de la existencia, pero eso mismo está indicando que, ordinariamente, no se distingue de ella. Ahora, en este punto Suárez supera a Tomás de Aquino claramente; si la causalidad es la acción, y ésta la dependencia del término, la creaturidad no inhiere en el ser sustancial, sino que o es la existencia del mismo o lo sostiene en ella (lo que, de hecho, es lo mismo). Todo esto es como decir: la entidad creada existe como «respectus» 0 actual referencia al Creador. La existencia creada «es» la causalidad.

¿Qué clase de acción es la creación? Acción sustancial, dice. Toda acción se reduce al predicamento en el que está su término. Pero el hacerse, la dependencia, y el término se dan a la vez; luego es como si el hacerse («fieri») se substantivara y eso fuera la relación de creaturidad. ${ }^{63}$

$59 C f:$ DM, 28, 1, 17-18: «Simili ergo analogia utimur ad declarandam perfectionem entitativam et virtutem activam rerum $[\ldots] »$.

60 «[...] vis agendi, praesertim in accidente, non est aliud ab entitate eius; vel si aliquo modo, saltem ratione, distinguatur, consequitur illam et commensuratur illi; ergo non potest accidens nobilius esse in agendo quam sit in essendo» (D.M. XVIII, 2, 5).

61 «Causa autem physica ac vera duplicem potest habere agendi modum, scilicet, vel naturaliter vel libere, seu necessario vel contingenter, et de his duobus modis agendi dicemus inferius, quia maxime pertinent ad explicandas tum perfectiones et naturas diversarum causarum, tum etiam seriem et connexionem effectuum universi et modum influendi seu concurrendi primae causae cum secundis [...]» (DM, XVII, 2, 6; cfr: XX, 2, 42). Ser por esencia es Ser Incausado, y ser «ab alio» es ser causado; $c f r$ XXVIII, 1, n. 7 y 16.

62 DM, 47,3, n. 12.

63 «Consiguientemente, la creación pasiva, en cuanto es vía hacia el término sustancial, queda reducida al predicamento de la sustancia; pero no tiene razón de pasión, por no hallarse en un sujeto. Por eso, en la medida en que ese 'fieri' se concibe como naturalmente anterior a su término, hay que conceder que no se da en un sujeto, sino que se concibe como en sí mismo, lo cual no es inconveniente, antes al contrario, más bien es una singular excelencia y modo de dependencia de la criatura. Pero en el mismo instante de tiempo en que es producida, se encuentra, por una unión íntima y cierta iden- 
La conservación en la existencia no es una acción distinta de la creación. ${ }^{64}$ Pero el término de la creación es uno y el mismo, aunque dure y cambie. ${ }^{65}$ Luego la conservación no es sino la condición de creatura, durando, pero sin innovación ni preterición. Así pues, lo que va cambiando y dura en el tiempo no es la existencia, como dependencia esencial del Creador, sino el término de ella (sustancia o esencia); he aquí, en suma, cómo para pensar el ente creado se aborda la incontradicción por un lado no proposicional, ni conceptual, diríase que «inobjetivo» pero muy real: la existencia perdura precisamente porque, al ser la misma, no vuelve a empezar ni cesa. ${ }^{66} \mathrm{Si}$ la existencia se conserva, no cesa ni se vuelve a otorgar, la contradicción sería, en términos de existencia actual, no de proposición lógica o axioma, cesar o volver a empezar: la existencia es incontradicción, así, en la forma de perdurar.

Ahora, si la conservación no una es reiteración de existencias sucesivas, ni su cesación, mucho menos puede ser la culminación: perdura dependiendo, remitiendo a Aquel que no depende. ${ }^{67}$ Luego es causalidad en acto, y por ahí se entrevé la existencia de Dios. La conservación del ser nos abre la perspectiva de una no-contradicción y una causalidad que no son proposiciones, sino existencia actual.

Suárez no lo subrayó, pero él estaba pensando aquí una dimensión del ser más honda que el ente o término del existir; este existir actual se compara con su sujeto como la unidad con la diversidad, como lo igual con lo diferente: «Porque la continuidad propiamente dicha sólo se da en una cosa divisible - dice-, mientras que la creación y la conservación son una acción indivisible, por lo que su unidad es mayor y su duración no tiene lugar por sucesión ni por verdadera continuidad, sino por la permanencia de una misma acción indivisible» (DM, 21, 2, 4).

La dependencia esencial es para el ente la misma existencia concreta. Por lo tanto, el ente está dependiendo mientras dura; lo que es como decir que su existir es perdurar, y que eso no es un proceso, ni nada de orden físico, sino metafísico. Se trata de la dependencia en el ser, no la de alguna forma adquirida. Si ser creatura es ser dependiente, entonces el existir de la creatura es conservado y remite al Ser Incausado. Y esto significa que esa relación de dependencia no es accidental, sino el mismo existir — perdurando— de la criatura. Aquí el Dr. Eximio ahonda su propia idea: creación

tidad, en el término mismo, no como en su sujeto, sino según la relación especial y propia por la que la vía se refiere al término; en ella no se requiere prioridad natural por parte del término, ya que no exige una verdadera causalidad, sino una simple terminación» (DM, XX, 4, n. 27).

64 «porque la misma indigencia que se da en el ser de la criatura en el primer instante en que es hecha, para no poder existir sin la acción de otro, se da también en ella mientras permanece en el ser» (DM, 21, 1, 16).

65 «Y no puede decirse con propiedad que esa conservación sea una repetida concesión del mismo ser, sino que, de igual modo que el ser mismo no es un ser repetido, sino que es un ser que permanece idéntico, así también el influjo por el que se conserva la cosa es el mismo, o la misma concesión del mismo ser» (DM, 21, 1, 16).

66 «Y no es superfluo este influjo, pues sin él las cosas creadas no serían autosuficientes [non sibi sufficerent] para mantenerse en el ser. Por eso, si faltase dicho influjo, inmediatamente volverían a la nada, no porque las cosas creadas se privasen a sí mismas de su ser — pues esto es contradictorio—, sino porque serían privadas de él por el Autor de su ser, y no mediante una acción contraria, sino mediante la suspensión de la acción necesaria para que pudiesen existir» (XXI, 1, 16).

67 «Rursus etiam colligitur necessitas conservationis sufficienter ex imperfectioni creati esse; nam si ex se tale esset ut posset vel per momentum permanere sine actuali influxu primae causae, etiam in primo momento vel in ipsa aeternitate esse posset sine tali influxu, neque ex intrinseca ratione sua postularet dependentiam ab alio, quod est proprium esse infinite perfecti» (DM, 21, 1, 17). 
y conservación, como acción que tiene por término una misma existencia, podrían ser pensadas como modalmente distintas, pero es superfluo y antinatural, concluye.

En conclusión: la metafísica de Suárez sólo piensa el existir como dependencia actual con un «pensar» que no es conceptual ni proposicional, puesto que el principio de causalidad y el de nocontradicción «son» el existir actual que depende y remite a Dios.

Santiago Fernández Burillo

Era Vall d'Aran, 27

E-25191 LLEIDA 